\title{
Influence of Slight Pressure Variations on the Mechanical and Tribological Properties of Ti/TiAlV/TiAlVN Coatings Produced by Magnetron Sputtering
}

\author{
Beatriz Gálviz-García ${ }^{1}$, D. Torres-Torres ${ }^{2}$, E. Martínez², Jhon J. Olaya-Flórez ${ }^{3} \&$ Elisabeth Restrepo-Parra ${ }^{1}$ \\ ${ }^{1}$ Laboratorio de Física del Plasma, Universidad Nacional de Colombia Sede Manizales, Km 9 vía al aeropuerto, \\ Manizales, Caldas, Colombia \\ ${ }^{2}$ Centro de Investigación de Materiales Avanzados (CIMAV), Monterrey, México \\ ${ }^{3}$ Grupo de investigación AFIS, Universidad Nacional de Colombia, Bogotá, Colombia \\ Correspondence: Elisabeth Restrepo-Parra, Senior Proffesor, Universidad Nacional de Colombia, Manizales, CA., \\ Cra. 27 No.64-60, Colombia Tel: 57-6-8879300 E-mail: erestrepopa@unal.edu.co
}

Received: August 4, 2018

doi:10.5539/mas.v12n10p171
Accepted: August 14, $2018 \quad$ Online Published: September 29, 2018

URL: https://doi.org/10.5539/mas.v12n10p171

\begin{abstract}
Ti/TiAlV/TiAlV(N) coatings were deposited by D.C magnetron sputtering technique. This experiment was carried out on $316 \mathrm{~L}$ stainless steel substrates, and it was produced varying the working pressure, in an environment composed by a mixture of $\mathrm{Ar} / \mathrm{N} 2$. While Ti and TiAlV layers were produced at a constant pressure, TiAlV(N) layers were grown at $0.6,0.8,0.9$ and $1.0 \mathrm{~Pa}$, for samples M1, M2, M3 and M4, respectively. After the production, morphological, compositional and structural properties of coatings were studied using techniques as $\mathrm{x}$-ray diffraction (XRD), energy dispersive spectroscopy (EDS), and atomic force microscopy (AFM). Next, mechanical and tribological properties such as hardness, Young's modulus, coefficient of friction, and adherence were evaluated, using nanoindentation, scratch test and ball on disc methods. XRD analysis evidenced that coatings crystallized in a salt rock FCC structure, and the crystallite size tended to increase with the increase of pressure. The XPS analysis allowed to demonstrate the presence of the doublets corresponding to metallic aluminum. Titanium was also found as well as the presence of oxygen as an oxidizing element of the coating. Regarding to the morphological analysis, it was observed an increase of the roughness when the coatings were grown, compared with the stainless substrates; moreover, no significant influence of the small pressure variation was observed on properties as hardness, coefficient of friction, and critical load.
\end{abstract}

Keywords: $316 \mathrm{~L}$ steel, bilayers, mechanical properties, tribology, TiAlVN

\section{Introduction}

Hard coatings have been widely studied for several technological applications, in order to increase the mechanical and tribological performance (Veprek, 2010) where cutting and forming tools, extrusion molds and machine pieces are involved (Yang, 2009) (Bobzin, 2006). Ti based hard coatings are possibly the most used because they have high corrosion resistance due to the formation of a hard and adherent oxide $\left(\mathrm{TiO}_{2}\right)$ that protects the material from the inorganic and organic acid agents. Ti based materials normally exhibit high ductility, high melting point, and an excellent biocompatibility. For instance, titanium nitride (TiN) is, perhaps, the most used material for hard coatings, due to its mechanical and tribological properties. These highlighted properties give to this material a great resistance to the critical conditions, generated during the tools or machine pieces exposition to industrial or biological environments; nevertheless, several shortcomings have been identified in TiN coated materials. Although TiN exhibits a high corrosion resistance, it suffers a high wear when is submitted to sliding and friction processes, especially in presence of biological fluids, when it is used in biomedical applications. Moreover, TiN coatings also exhibit other unsatisfactory aspects, such as high fragility and peeling, which worsen at hightemperature, restricting their potential applications (Venkatesh, 2009). One way to improve the behavior of these coatings consists in adding other elements. For instance, by including $\mathrm{Zr}$, the material can improve its chemical stability and mechanical performance, increasing the hardness and the Young's modulus. Other option consists in including $\mathrm{Al}$, forming compounds as TiAlN coatings that, compared to TiN coatings have exhibited a better wear resistance, high oxidation temperature and high binding force (Kumar, 2015). On the other hand, in the literature 
it was found that, by adding $\mathrm{V}$ to TiN, an improvement can be observed in the mechanical and tribological performance (Montero-Ocampo, 2015). Combining the last two options, adding $\mathrm{Al}$ and $\mathrm{V}$, a better performance can be obtained, decreasing the coefficient of friction (COF) of the surface at higher temperatures (Kumar, 2015); for instance, including V to TiAlN and producing a TiAlVN solid solution, in a face-centered cubic (fcc) structure, a material that exhibits high hardness and Young's modulus can be obtained (Pfeiler-deutschmann, 2015). These conditions can decrease the COF in a 60\% at high temperatures (Kumar, 2015). On the other hand, in the literature, there are several reports showing studies of TiAlVN/TiN systems. For instance, TiAlN/TiAlVN multilayers were produced by cathodic arc evaporation, showing an improvement of hardness and Young's modulus (MonteroOcampo, 2015) (Shimizu, 2015). Yi et al., (Yi, 2016) produced TiAlN multilayers on Ti6Al4V substrates by using the magnetron sputtering technique, where some deposition parameters were varied in order to determine their influence on the hardness, Young's modulus, COF, wear and corrosion resistance. Krishna et al. (Krishna, 2012) evaluated the tribological performance of Ti6A14V coatings reinforced with TiN nanoparticles. These systems exhibited a decrease of $40 \%$ in the wear rate compared with TiN. Finally, parameters of deposition such as substrate temperature, bias voltage, and deposition pressure strongly affect the coatings structure, morphology and performance, in fact, the pressure has high influence on reactive processes of coatings production (Hatem, 2017), (Biswas, 2017), (Shan, 2014), (Shimizu, 2017). The need to use biomaterials related to the mechanical properties has led to the use of methodical alloys with excellent biocompatibility, chemical passivity, and the adequate properties for good behavior in a long time (Gómez, 2014). Titanium is a material more compatible than others, for instance, than $\mathrm{CrCo}$, since the body cells colonize the surface of the Ti alloy in an easier way, being more resistant against the bacteria (Cordero, 1996).

Although there exist some studies of TiAlVN coatings as monolayers and multilayers, deeper investigations of the influence of small variations of deposition pressure on the mechanical and tribological performance are required for understanding the physics behind their behavior. Pressure is an important parameter to be considered when producing coatings, since the ions of the base material as TiAlV when are migrating from the target can reach the substrate at an enough energy for improving the coating properties such as adherence, mechanical, and tribological behavior; then, this improvement can benefit applications in biocompatibility.

The aim of this work is to produce Ti/TiAlV/TiAlVN bilayers using the magnetron sputtering technique, varying the pressure in a small range (between 0.6 and $1 \mathrm{~Pa}$ ); after the production, morphological, compositional, and structural properties of bilayers were studied using techniques as x-ray diffraction (XRD), energy dispersive spectroscopy (EDS) and atomic force microscopy (AFM). After that, mechanical and tribological properties such as hardness, Young's modulus, COF, and adherence were evaluated, using nanoindentation, scratch test and ball on disc. Properties were correlated for determining the best conditions of production.

\section{Method}

\subsection{Coatings Production}

Coatings were produced using a commercial DC magnetron sputtering equipment with a vacuum system intercovamex $\mathrm{H} 2$, being grown on substrates of 316L stainless steel with dimensions of $1 \mathrm{~cm}$ height, $2 \mathrm{~cm}$ width and $1 \mathrm{~mm}$ thickness. Before the coatings production, samples were deeper polished using an electropolished system, applying perchloride acid solution $(25 \mathrm{ml})$ and ethanol $(75 \mathrm{ml})$ (Orikasa, 2009). Targets of Ti6Al4V and Ti with $99.9 \%$ purity and 2 inches diameter were used and placed at the cathode, while the substrates were placed at the anode, separated by $10 \mathrm{~cm}$. Layers of Ti, TiAlV using an atmosphere of Ar. On the other hand, for the $\operatorname{TiAlV}(\mathrm{N})$, a mixture of argon and nitrogen using a gas flow ratio of Ar:N2=25:5 was established for the experiment. The pressures used in this work were 0.6, 0.8, 0.9 y $1.0 \mathrm{~Pa}$ and the samples were named M1, M2, M3 and M4, respectively. Coatings were grown at a power of $150 \mathrm{~W}$, bias voltage of $-50 \mathrm{~V}$, room temperature, and times of 30 min for Ti and TiAlV layers and $60 \mathrm{~min}$ for the TiAlVN layer.

\subsection{Coatings Characterization}

$\mathrm{X}$-ray diffraction (XRD) was used to study the structure and phases formation in the coatings. The XRD patterns were obtained using Bruker D8 Advance X-ray diffractometer using a $\mathrm{Cu} K \alpha$ radiation $(\lambda=0.154060 \mathrm{~nm})$ in thin film geometry (glancing angle $=0.02^{\circ}$ ), with a step of $0.015^{\circ}$. The compositional analysis of the Ti/TiAlV/TiAlNV coatings was performed using the EDS equipment attached to a Model Nova Nano SEM 200 Make FEI. Atomic force microscopy, ASYLUM RESEARCH, model MFP3D-SA was used to determine the surface roughness and grain size of the TiAlVN coatings. Images were taken in areas of $1 \mu \mathrm{m} \times 1 \mu \mathrm{m}$ with a resolution of approximately $3 \mathrm{~nm}$.

The effect of the deposition pressure on the coatings hardness was studied using a nanoindentation hardness tester HYSITRON Model TI 950, with a diamond tip BERKOVICH, $142.3^{\circ}$ total angle and nominal radius of curvature 
of $150 \mathrm{~nm}$, using a load of $15 \mathrm{mN}$ and a Berkovich diamond indenter. Scratch tests were performed with a CSM Revetest Xpress Scratch Tester using a Rockwell C indenter of $200 \mu \mathrm{m}$ radius equipment, employing a linearly increasing normal load of 0-20 N. A constant scratch speed of $689 \mathrm{rev} / \mathrm{s}$ was used for the scratch tests with a scratch length of $5 \mathrm{~mm}$. A stainless steel spherical scratch tip of $5 \mathrm{~mm}$ diameter was used to conduct the tests.

\section{Results}

\subsection{X-Ray Diffraction Analysis}

Figure 1 shows the diffractograms of the steel and coatings of Ti/TiAlV/TiAlV(N) growth at different pressures. In these diffractograms, the steel peaks and two other peaks that correspond to the TiAlVN are identified. These two last peaks are belonging to planes (111) and (200) that are characteristic of a salt rock FCC structure. It is necessary to consider that TiAlVN is formed from a solid solution of the TiN, AlN and VN compounds, which lattice parameters are $4.24 \AA$ (Carrasco, 2002), $3.11 \AA$ (Nilsson, 2016) and $4.13 \AA$ (Wang, 2016), respectively. Table 1 shows the lattice parameters and the grain sizes of the samples produced in this work. Considering these aspects, and that $\mathrm{Ti}$ is the metallic element that is found in a greater proportion within the TiAlVN compound, the latter must be formed from the incorporation of small amounts of $\mathrm{Al}$ and $\mathrm{V}$ atoms into the TiN lattice. For the case of sample M1, the lattice parameter increases, compared to that of TiN, as shown in Table 1 (Pfeiler-deutschmann, 2015). This is due to the incorporation of small amounts of $\mathrm{Al}$ and $\mathrm{V}$ into the TiN lattice, as previously was mentioned (Nilsson, 2016), (Wang, 2016). Values found in the literature are very similar to those obtained in this work (Arias, 2006). Sample M1 also shows a higher percentage of nitrogen incorporation. The reason is that, at lower pressures, lower quantity of argon ions can produce inelastic collisions between heavy particles within the plasma; this causes that greater amount of nitrogen ions, present in the plasma, can reach the surface; however, as the pressure increases, a decrease in the lattice parameter of the compound is observed; this can be due to a lower nitrogen incorporation, because, when increasing the pressure, the quantity of argon ions that produce inelastic collisions increase, therefore, the nitrogen ions lose energy.

On the other hand, the evolution of the crystallite size with respect to the growth pressure is also observed in Table 1. According to these results, sample M1 presents the largest crystallite size, because this sample exhibited the highest percentage of vanadium, which is the atom with the largest diameter of the compound and the highest lattice parameter, compared to the other three samples.

\subsection{Energy Dispersive Spectroscopy (EDS)}

Table 2 shows the results obtained by EDS, where the elements that form the coatings produced at different pressures are appreciated. According to the results of table 2, the presence of oxygen on the surface of the coatings, was identified, which could be due to the exposure of the films to the environment when extracting the samples from the reaction chamber. At lower pressure, an increase in the percentage of $\mathrm{Al}$ is shown. The reason for this is that $\mathrm{Al}$ is the lightest of the metals forming the coating, and at low pressures, it is easier to transport, together with the nitrogen, which also increases. On the other hand, no strong variation was observed in the heavier metal elements such as vanadium. This behavior can be attributed to the low range of pressure variation carried out in this work. On the other hand, there is a tendency to increase the Ti in the samples, as the pressure increases. This behavior is caused by the competition between metallic elements that occupy the sites of the lattice; since there are fewer sites occupied by Al, these sites can be filled by titanium ions.

It is also evident that the samples that contain a greater quantity of nitrogen also have less oxygen; this effect may occur because these two elements, which have similar dimensions and valences, compete to occupy the sites in the compound lattice.

The chemical maps of the samples obtained using EDS show a similar behavior in all samples. In figure 2, the distribution of the elements, or chemical mapping, present on the surface of the M4 sample (as an example) is observed. There is a homogeneous distribution of $\mathrm{Al}, \mathrm{Ti}, \mathrm{V}, \mathrm{O}$ and $\mathrm{N}$ on the surface coating; this homogeneity is an indication that the growth of the coatings was uniform and successful.

\subsection{Atomic Force Microscopy (AFM)}

Figure 3 shows the 3D images of the topography obtained by AFM in non-contact mode in an area of $1.0 \mu \mathrm{m} \mathrm{X}$ $1.0 \mu \mathrm{m}$. From these figures, it was observed a granular growth. Furthermore, these images allow to determine the roughness and the grain size of the bilayers. The grains formation in figure 3 can be an indication that the microstructure of the coatings can be represented by the model of Movchan and Demchishin (Boxman, 1995), which is characterized by having sharp columns with dome-shaped terminations. In these zones, the surface diffusion is insufficient to overcome the geometric characteristics that occur when projecting the coating material on the surface of the substrate. Then, there are open borders between columns, forming dense coverings, this are 
called "mosaic-shaped surface" (Pearce, 2012).

Table 3 shows the results of the grain size and the average roughness ( $\mathrm{Ra}$ ) for the coatings. According to these results, at higher pressure, the grain size and the average roughness, Ra, tend to decrease; this can be due to a lower nitrogen incorporation, according to the EDS results, since, when increasing the pressure, the quantity of argon ions that produce inelastic collisions increases. This increase is due to a decreasing in the mean free path of the Ar ions, generating a decrease in the momentum and energy. This effect makes the particles hit the surface with lower energy, therefore, producing less damage to the surface (Quesada, 2006).

At lower pressures, the grain size is higher, compared to uncoated steel. This is because there are less number of ions that collide and interfere with the energy at which they can reach the surface of the substrate. However, at higher pressures, the grain size decreases, even below the steel grain size; this is due to the tendency to increase the oxygen, previously described in EDS, forming a greater amount of surface oxides, and generating more grain boundaries (Ratner, 1996). Other visible result is the increase in the average roughness in all the coated samples, compared with the steel roughness. This behavior is an atypical characteristic of the coatings growth process, since, there is a coalescence of islands, and domes, formed on the surface. The generation of these domes causes greater differences in surface heights.

\subsection{Scanning Electron Microscopy}

In Figure 4, the SEM micrograph of the Ti/TiAlV/TiAlV(N) films grown at different pressures is observed. In this figure, the formation of grains is evident. Furthermore, it is remarkable that, as the pressure increases a more surface compaction was observed. However, the sample M4 breaks with this trend since its surface seems to be less compact. This kind of formation is due to the coating thickness is very thin, exhibiting a tendency to StranskiKrastanov growth, showing monolayers in a horizontal way and, subsequently, a growth as islands vertically produced on the monolayers already formed.

In many cases, the coatings are formed due to the coalescence of the islands, producing several defects and grain boundaries. The grains that coalesce are randomly oriented and they form polycrystalline films (Li, 2001). This behavior is specially observed in the case of sample M4 included in Figure 4, where the coalescence of the grains and their growth seem to be in the form of islands

\subsection{Surface Nano-Hardness and Elasticity}

Table 4 shows the values of nanoindentation and Young's modulus obtained for coatings of Ti/TiAlV/TiAlV(N), varying the pressure and uncoated steel. According to this table, the coatings of Ti/TiAlV/TiAlV(N) increased the hardness unlike $316 \mathrm{~L}$ steel. This behavior is due to the formation of a harder layer on the substrate.

Considering that variations in hardness are within the range of the standard deviation, a trend for these pressure changes cannot be clearly defined. This may be due to the pressure variation is not sufficient to produce changes in the process, to generate an appreciable influence on the mechanical properties. On the other hand, the values obtained are adequate, because a hardness higher than $10 \mathrm{GPa}$ would not allow the load to be properly distributed on the surface and a good coupling between the base material and the coating would not be well achieved (Eli, 2014). It is also observed that the variations of the Young's modulus in the coatings are in the range of the standard deviation; then, a clear tendency cannot be defined. Again, because of this low range of pressure variations is not enough for influencing the collision processes of particles during the growth. These values are similar to those exhibited by titanium alloys (Ratner, 1996).

The range of the values obtained for the Young's modulus, indicated that the plastic behavior of the coating of TiAlV(N) on the steel $316 \mathrm{~L}$, could be suitable for being used in biocompatible applications such as orthopedic implants, since it allows to resist loads without being deformed during its performance when it is implanted. In addition, when making a comparison between the coated samples and the $316 \mathrm{~L}$ steel, a slight increase in hardness is observed. The coatings produced by the magnetron sputtering technique are a viable option to improve the performance of coatings with osteo-compatible uses, since, by increasing the hardness, an increase in wear resistance is achieved, as it is shown below.

\subsection{Wear tests}

For a biological or biocompatible purpose, a good resistance to the wear of the coating is very important, since the coating is the material that is in contact with the tissues and fluids of the body. A low resistance to wear leads to the generation of particles that could not only generate adverse responses in the organism, but also lead to the disappearance of the coating, so the tissues would be in contact with a metal that is not compatible at al (Park, 2007). 
The ball on disc technique was used to obtain the coefficient of friction (COF) and the critical loads (LC), to determine the point of failure of the coatings. Figure 5 shows images taken with Bruker ContourGT-K interferometer/optical microscope for the track left by the indenter, while moving on the surface (Komanduri, 2000).

According to Figure 5 there is an adhesive failure, where flakes are formed as shown in Figure 6. Then, later delamination occurs, showing material detachment and subsequent cracking of the coating, mainly at the edges produced by tearing of the coating (Dobrzański, 2006). On the other hand, the procedure for obtaining LC is shown in figure 6, for the sample M3. There is not a considerable variation in the critical load, except for the case of M4, that is the sample grown at the highest pressure. Moreover, multilayer coatings have the function of improving adhesion, and this function is performed by the first layer. Therefore, the outermost layers are grown normally to improve the hardness and wear resistance, to decrease the coefficient of friction and to increase the chemical stability. The use of multilayer coatings allows to increase the useful life of the materials, contributing a decrease in production costs (Geetha, 2014).

Figure 7 shows the behavior of the coefficient of friction (COF) of the samples with coatings of Ti6Al4V $(\mathrm{N})$ in time. The tests were developed with a load of $10 \mathrm{~N}$. In this figure it is observed at low times an abrupt increase of the $\mathrm{COF}$, this is because a greater force is required for the pin to overcome the inertia of the initial contact with the surface of the coatings. Once this initial inertia has been overcome, the COF stabilizes.

It can be seen in Table 4 that the COF is similar for all samples. There is a direct relationship between the coefficient of friction and the roughness. A rougher surface suffers greater roughness contact between the surface and the pin. Therefore, since no significant changes in the roughness were observed in the samples, there are not great changes in the formation of asperities and, therefore, the plastic and mechanical formation remains in the same range during the sliding process. Since the debris is accumulated in the tracks, it behaves like a third body in this process of sliding. The fact that this debris remains more or less constant, generate stability in the coefficient of friction (Ali, 2008), (Svahn, 2003).

The coatings of Ti6Al4V (N) present coefficients of friction lower than those reported in the literature (Chavda, 2016); moreover, coefficients of friction between 0.2 and 0.7 are reported for titanium alloys.

\section{Conclusions}

Ti/TiAlV/TiAlV(N) coatings on stainless steel were successfully produced using DC magnetron sputtering, at pressure values of $0.6,0.8,0.9$ and 1.0 Pa. Materials exhibited the salt rock FCC structure with lattice parameter that indicated the formation of a solid solution of the compounds TiN, AlN and VN, being closer to the lattice parameter of TiN, since $\mathrm{Ti}$ is the metallic element which was found in a greater proportion within the TiAlVN compound. According to EDS analysis, samples grown at lower pressure exhibited an increase in the percentage of $\mathrm{Al}$, possibly due to $\mathrm{Al}$ is the lightest of the metals that form the coating, being easier to be transported. Moreover, no strong changes were observed in the heavier metal elements such as vanadium with the pressure. The grain size measured using AFM, tended to increase, while the roughness does not show a significant variation with the pressure. On the other hand, no greater influence of the pressure was observed on hardness, coefficient of friction and critical load. Nevertheless, values of hardness and COF can be suitable for biocompatible applications

\section{Acknowledgments}

Authors gratefully acknowledge the financial support provided by Dirección Nacional de Investigaciones of the Universidad Nacional de Colombia under the project 34705. Authors also want to acknowledge to Centro de Materiales Avanzados (CIMAV) Monterrey- México, for the analysis with XPS, AFM, and Nanoindentation techniques, used in this work.

\section{References}

Ali M., Hamzah, E., \& Radzi, T. M. (2008). Friction coefficient and surface roughness of TiN-coated HSS deposited using cathodic arc evaporation PVD technique. Ind. Lubr. Tribol., 60, 121-130. https://doi.org/10.1108/00368790810871048

Arias, D. F., Arango, Y. C., \& Devia, A. (2006). Study of TiN and ZrN thin films grown by cathodic arc technique, Appl. Surf. Sci., 253, 1683-1690. https://doi.org/10.1016/j.apsusc.2006.03.017

Biswas, B., Purandare, Y., Sugumaran, A. A., Loch, D. A. L., Creasey, S., Khan, I., Ehiasarian, A. P., \& Hovsepian, P. E. (2017). Defect growth in multilayer chromium nitride/niobium nitride coatings produced by combined high power impulse magnetron sputtering and unbalance magnetron sputtering technique, Thin Solid Films, 636, 558-566. https://doi.org/10.1016/j.tsf.2017.06.027 
Bobzin, K., Lugscheider, E., Nickel, R., \& Immich, P. (2006). $\left(\mathrm{Cr}_{1-\mathrm{x}}, \mathrm{Al}_{\mathrm{x}}\right) \mathrm{N}$ ein Review über ein vielseitig einsetzbares Schichtsystem, Materwiss. Werksttech., 37, 833-841. 10.1002/mawe.200600048.

Boxman, R. L., Sanders, D. M., \& Martin, P. J. (1995). Handbook of Vacuum Arc Science and Technology: Fundamentals and Applications. Noyer Publications, Californa, 1995.

Carrasco, C. A., Vergara, V., Benavente, R., Mingolo, N., \& Ríos, J. C. (2002). The relationship between residual stress and process parameters in TiN coatings on copper alloy substrates, Mater. Charact., 48, 81-88. https://doi.org/10.1016/S1044-5803(02)00256-5

Chavda, M. R., Dave, D. P., Chauhan, K. V., \& Rawal, S. K. (2016). Study of Tribological Behavior for Chromium Based Coatings Deposited on Conventional Materials, Proc. Technol., 23, 91-97.

Cordero, J., Munuera, L., \& Folgueira, M. D. (1996). The influence of the chemical composition and surface of the implant on infection, Injury, 27, S/C34- S/C37. https://doi.org/10.1016/0020-1383(96)89030-9

Dobrzański, L. A., Pakuła, D., Křiž, A., Soković, M., \& Kopač, J. (2006). Tribological properties of the PVD and CVD coatings deposited onto the nitride tool ceramics, J. Mater. Process. Technol., 175, 179-185. https://doi.org/10.1016/j.jmatprotec.2005.04.032

Eli, Y. T. D. E. T., \& Mediante, N. (2014). Relation between the mechanical and tribological properties of nitrided Ti6Al4V eli by glow discharge plasma Cienc. e Ing., 24, 7-21.

Geetha, B., Priyadarshini, Aich, S., \& Chakraborty, M. (2014). On the microstructure and interfacial properties of sputtered nickel thin film on Si (100), Bull. Mater. Sci., 37, 1265-1273. https://doi.org/10.1007/s1203

Gómez, L. S., \& Quintero, A. F., Peña Ballesteros, D. Y., \& Estupiñan, D. H. A. (2014). Obtención, caracterización y evaluación in vitro de recubrimientos de policaprolactona-quitosano sobre la aleación Ti6Al4V tratada químicamente, Revista de Metalurgia, 50, 4. http://dx.doi.org/10.3989/revmetalm.021

Hatem, A., Lin, J., Wei, R., Torres, R. D., Laurindo, C., \& Soares, P. (2018). Tribocorrosion Behavior of Low Friction Tisicn Nanocomposite Coatings Deposited on Titanium Alloy For Biomedical Applications, Surf. Coat. Technol., 347, 1-12. https://doi.org/10.1016/j.surfcoat.2018.04.049

Komanduri, R., Chandrasekaran, N., \& Raff, L. M. (2000). MD simulation of indentation and scratching of single crystal aluminum, Wear, 240, 113-143. https://doi.org/10.1016/S0043-1648(00)00358-6.

Krishna, V., Bhat, A., Bose, S., \& Bandyopadhyay, A. (2012). Laser Processed TiN Reinforced Ti6Al4V Composite Coatings, J. Mech. Behav. Biomed. Mater., 6, 9-20. https://doi.org/10.1016/j.jmbbm.2011.09.007

Kumar, D. D., Kumar, N., Kalaiselvam, S., Dash, S., \& Jayavel, R. (2015). Tribo-mechanical properties of reactive magnetron sputtered transition metal carbide coatings, Tribol. Int., $88,25$. https://doi.org/10.1016/j.triboint.2017.04.031

Li, T. S., Li, H., \& Pan, F. (2001). Microstructure and nanoindentation hardness of Ti/TiN multilayered films, Surf. Coat. Technol., 137, 225-229. https://doi.org/10.1016/S0257-8972(00)01096-3

Montero-Ocampo, C., Ramírez-Ceja, E. A., \& Hidalgo-Badillo, J. A. (2015). Effect of codeposition parameters on the hardness and adhesion of TiVN coatings, Ceram. Int., 41, 11013-11023. https://doi.org/10.1016/j.ceramint.2015.05.046

Nilsson, D., Janzén, E., \& Kakanakova-Georgieva, A. (2016). Lattice parameters of AlN bulk, homoepitaxial and heteroepitaxial material J. Phys. D: Appl. Phys, 47, 175108. https://doi.org/10.1088/0022-3727/49/17/175108.

Orikasa, H., Akahane, T., Okada, M., Tong, Y., Ozaki, J., \& Kyotani, T. (2009). Electrochemical behavior of carbon nanorod arrays having different graphene orientations and crystallinity, J. Mater. Chem., 19, 4615. https://doi.org/10.1039/B900747D

Park, J., \& Lakes, R. S. (2007). Biomaterials: An introduction: Third edition. Springer, Iowa.

Pfeiler-deutschmann, M., Mayrhofer, P. H., Chladil, K., Penoy, M., Michotte, C., Kathrein, M., \& Mitterer, C. (2015). Effect of wavelength modulation of arc evaporated Ti-Al-N/Ti-Al-V-N multilayer coatings on microstructure and mechanical/tribological properties, Thin Solid Films, 581, 20-24. https://doi.org/10.1016/j.tsf.2014.10.051

Quesada, F., Mariño, A., \& Restrepo, E. (2006). TiAlN coatings deposited by r.f. magnetron sputtering on previously treated ASTM A36 steel, Surf. Coat. Technol., 201, 2925-2929. https://doi.org/10.1016/j.surfcoat.2006.06.018

Ratner, B. D., Allan, H. S., Schoen, F. J., \& Lemons, J. E. (1996). Biomaterials Science: An Introduction to 
Materials in Medicine. Academic Press USA.

Shan, L., Wang, Y., Li, J., \& Chen, J. (2014). Effect of N2 flow rate on microstructure and mechanical properties of PVD CrNx coatings for tribological application in seawater, Surf. Coat. Technol., 242, 74-82. https://doi.org/10.1016/j.surfcoat.2014.01.021

Shimizu, T., Komiya, H., Teranishi, Y., Morikawa, K., Nagasaka, H., \& Yang, M. (2017). Pressure dependence of (Ti, Al)N film growth on inner walls of small holes in high-power impulse magnetron sputtering, Thin Solid Films, 624, 189-196. https://doi.org/10.1016/j.tsf.2016.09.041

Shimizu, T., Teranishi, Y., Morikawa, K., Komiya, H., \& Watanabe, T. (2015). Impact of pulse duration in high power impulse magnetron sputtering on the low-temperature growth of wurtzite phase (Ti,Al)N films with high hardness, Thin Solid Films, 581, 39-47. https://doi.org/10.1016/j.tsf.2014.11.076.

Svahn, F., Kassman-rudolphi, Å., \& Wallén, E. (2003). The influence of surface roughness on friction and wear of machine element coatings. Wear, 254, 1092-1098. https://doi.org/10.1016/S0043-1648(03)00341-7

Venkatesh, B. D., Chen, D. L., \& Bhole, S. D. (2009). Effect of heat treatment on mechanical properties of Ti6Al-4V ELI alloy, Mater. Sci. Eng. A, 506, 117-124. https://doi.org/10.1016/j.msea.2008.11.018

Veprek S., Zhang R. F., Veprek-heijman M. G. J., Sheng S. H., \& Argon A. S. (2010). Superhard nanocomposites: Origin of hardness enhancement, properties and applications, Surf. Coat. Technol., 204, 1898-1906. https://doi.org/10.1016/j.surfcoat.2009.09.033

Wang, S., Yu, X., Zhang, J., Wang, L., Leinenweber, K., He, D., \& Zhao, Y. (2014). Crystal structures, elastic properties, and hardness of high-pressure synthesized CrB2 and CrB4, Cryst. Growth Des., 36, 279-287. https://doi.org/10.3103/S1063457614040066

Yang, S., Cooke, K. E., Li, X., McIntosh, F., \& Teer, D. G. (2009). CrN-based wear resistant hard coatings for machining and forming tools, J. Phys. D. Appl. Phys., 42, 104001. https://doi.org/10.1088/0022$3727 / 42 / 10 / 104001$

Yi, P., Peng, L., \& Huang, J. (2016). Multilayered TiAlN films on Ti6Al4V alloy for biomedical applications by closed field unbalanced magnetron sputter ion plating process, Mater. Sci. Eng. C., 59, 669-676. https://doi.org/10.1016/j.msec.2015.10.071

\section{Copyrights}

Copyright for this article is retained by the author(s), with first publication rights granted to the journal.

This is an open-access article distributed under the terms and conditions of the Creative Commons Attribution license (http://creativecommons.org/licenses/by/4.0/). 